University) G. W. Hoskins, (Department of the Navy) and J. R. Engel, RCA (Astro-Electronics Division)

Low-Frequency Radio Integrated with Dead-Reckoning for Automatic Vehicle Location. Dr J. D. Last (University College of North Wales).

Land Navigation Methodology: an Investigation of a Global Positioning System (GPS) for Surface Vehicles. S. B. Richter and D. M. Parry (Aydin Computer Systems)

\title{
Hans Christian Freiesleben
}

TH E death, on 14 November 1985 at the age of 92 , of Dr H. C. Freiesleben has robbed the Institute of one of its Honorary Members - and the science of navigation of one of its finest friends. He entered the service of the Deutsche Seewarte in 1930 when the physical problems of the dip of the sea horizon were uppermost. His authoritative work on the subject, both theoretical and experimental, commanded the greatest respect and still provides a firm basis for a proper understanding of the problem. His first paper in the Journal, in 1951, gave a comprehensive account of this work; his last one, in 1984, was on the history of the portolan chart - an indication of the width of his navigational interest.

After the war he joined the Deutsche Hydrographische Institut where he became Deputy Director of the Division of Geophysics and Astronomy and Head of its section on Methods and Scientific Bases of Navigation. In some thirty-five papers to the Journal - to him a foreign-language publication - he covered, with thoughtful reasoning, many of the post-war developments at sea. Among them were the early physiological and psychological problems of using radar, the geometry of Decca, the mathematics of collision-avoidance manoeuvres, and satellite navigation. This did not deflect his interest from the tables and graphs that were so much a part of astronomical navigation before the war. In $195 \mathrm{I}$ he published, in association with Hopfner and Roediger, Navigation, a remarkable work which dealt, within 300 pages, in an authoritative manner with practically every subect the marine navigator needed to master his trade.

He played a significant part in the formation of the International Association of Institutes of Navigation and later was to serve as a member of the IAIN committee concerned with compiling an annotated list of tables and methods for astronomical navigation: his contributions were both comprehensive and admirable in detail.

Dr Freiesleben was by nature a scholar, quiet and dignified, with a deep interest in navigation and a determination to set authoritative standards. He was a charming person to meet, and to write to - his arguments had reason and were put forward with reasonableness. He was elected a Member of the Institute in 1963 , a Fellow in 1966 and an Honorary Member in 1972 .

D. H.S. 